\title{
Quantum chemical studies of carbon-13 equilibrium fractionation in ion-molecule reactions
}

\author{
Lawrence L. Lohr \\ Department of Chemistry, University of Michigan, Ann Arbor, Michigan 48109-1055
}

(Received 31 October 1997; accepted 10 February 1998)

\begin{abstract}
$A b$ initio computational quantum chemical methods are used to calculate reduced partition function ratios for all isotopomers of $\mathrm{CO}, \mathrm{HCO}^{+}$, and $\mathrm{HOC}^{+}$involving the nuclides ${ }^{1} \mathrm{H},{ }^{2} \mathrm{H}(\mathrm{D}),{ }^{12} \mathrm{C},{ }^{13} \mathrm{C}$, ${ }^{16} \mathrm{O}$, and ${ }^{18} \mathrm{O}$. The ratios are used to calculate equilibrium constants for the reaction pairs $\mathrm{HCO}^{+} / \mathrm{CO}, \mathrm{HOC}^{+} / \mathrm{CO}$, and $\mathrm{C}^{+} / \mathrm{CO}$. Both simple proton transfers and more complex isotopic variants involving the breaking and reforming of $\mathrm{CO}$ bonds are considered. The probable pathways for the $\mathrm{HCO}^{+} / \mathrm{CO}$ and $\mathrm{C}^{+} / \mathrm{CO}$ exchange reactions are explored in detail using high-accuracy quantum chemical calculations. It appears most likely that the $\mathrm{HCO}^{+} / \mathrm{CO}$ reaction proceeds through exothermic formation of the linear adduct $\mathrm{OCHCO}^{+}$with $D_{\infty h}$ symmetry. Similarly, the $\mathrm{C}^{+} / \mathrm{CO}$ reaction proceeds along a spin-allowed pathway with exothermic formation of the linear adduct $\mathrm{COC}^{+}$with $D_{\infty h}$ symmetry. An alternate but higher energy spin-allowed pathway for the $\mathrm{C}^{+} / \mathrm{CO}$ reaction passes through a transition state with only $C_{s}$ symmetry and a locally stable intermediate with $C_{2 v}$ symmetry. In the ISM these reactions may proceed by these direct pathways or indirectly through coupled exothermic reaction pairs involving other species to achieve ${ }^{13} \mathrm{C} /{ }^{12} \mathrm{C}$ isotope exchange. (C) 1998 American Institute of Physics. [S0021-9606(98)00719-3]
\end{abstract}

\section{INTRODUCTION}

Experimental and theoretical studies of stable isotope fractionations have played an important role in many aspects of chemistry, including geo- and cosmochemistry, for over half a century, dating from the pioneering studies of Urey, ${ }^{1}$ who presented partition functions for the ${ }^{12} \mathrm{C}$ and ${ }^{13} \mathrm{C}$ variants of the carbon species $\mathrm{C}$ (diamond), $\mathrm{CO}, \mathrm{CO}_{2}, \mathrm{CO}_{3}{ }^{2}$, $\mathrm{HCN}$, and $\mathrm{CN}^{-}$and equilibrium constants for their isotope exchange reactions, as well as similar results for species containing other stable isotopes. While Craig ${ }^{2}$ discussed the difficulties of applying Urey's methods to fractionation in solidgas equilibria, many such studies followed, including those by Bottinga, ${ }^{3-5}$ and Bottinga and Craig, ${ }^{6}$ with an emphasis on equilibria involving $\mathrm{C}$ (graphite and diamond), $\mathrm{CO}_{2}$, $\mathrm{CaCO}_{3}$, and $\mathrm{H}_{2} \mathrm{O}$. These results and others were summarized by Richet et al., ${ }^{7}$ while equilibrium isotope effects in general were reviewed by Bigeleisen et al. ${ }^{8}$ Isotope fractionation in interstellar clouds, including that of $\mathrm{C}$ isotopes, was discussed in detail in Watson's review ${ }^{9}$ of interstellar molecular reactions. Smith and Adams carried out laboratory studies ${ }^{10}$ of fractionation in the reactions of $\mathrm{C}^{+}$and $\mathrm{HCO}^{+}$with $\mathrm{CO}$, and discussed the implications for interstellar reactions. A representative study ${ }^{11}$ of the ${ }^{12} \mathrm{C} /{ }^{13} \mathrm{C}$ ratio in comets is that based on studies of the $\mathrm{CN}$ radical in comet Halley. Further carbon isotope studies include those of $\mathrm{CO}$ and $\mathrm{C}^{+}$in the Orion molecular cloud. ${ }^{12}$ Quite recently $\mathrm{C}$ isotope fractionation studies played an important role in developing evidence for life on earth approximately $3800 \mathrm{Myr}_{\mathrm{ago}}{ }^{13}$ and possibly on Mars. ${ }^{14}$

More relevant to our present study are the many investigations of the relationships between observed isotope fractionations in the ion-molecule reactions occurring in molecular clouds to nuclear abundances in the interstellar medium (ISM). Townes ${ }^{15}$ discussed the implications of observed isotopic abundances in interstellar clouds, while Wannier $^{16}$ discussed the implications of Watson's ${ }^{9}$ proposed chemical models for isotope fractionations for evolution of the ISM. Herbst and Klemperer ${ }^{17}$ pioneered model studies of ion-molecule reactions; the latter studies were reviewed in detail by Green. ${ }^{18}$ Other reviews include those by Smith and Adams, ${ }^{19}$ Kroto, $^{20}$ and Dalgarno. ${ }^{21}$ In addition, the very recent text by Cowley ${ }^{2}$ contains an excellent chapter on isotope effects. Observations of ${ }^{12} \mathrm{C} /{ }^{13} \mathrm{C}$ ratios in molecular clouds have continued, ${ }^{23,24}$ as have model studies ${ }^{25,26}$ of the chemical reactions which likely occur in the ISM. A recent review $^{27}$ of abundances in the ISM concludes that there most likely is a statistically meaningful dependence of the ${ }^{12} \mathrm{C} /{ }^{13} \mathrm{C}$ ratios in molecular clouds on the distance of the clouds from the galactic center, with this ratio being smallest ( $\sim 20-25)$ near the center, as in the clouds Sgr (Sagittarius) A and B, and increasing with distance to the solar system value of 89 .

In our study we have used computational quantum chemical methods to calculate reduced partition function ratios and equilibrium constants for ${ }^{13} \mathrm{C}$ equilibrium fractionations in ion-molecule reactions, with particular emphasis on the $\mathrm{HCO}^{+} / \mathrm{CO}$ and $\mathrm{HOC}^{+} / \mathrm{CO}$ reaction pairs. We have also explored in detail the structures and energetics of various states of the $\mathrm{C}_{2} \mathrm{O}^{+}$ion as may be involved in the isotope exchange reaction between $\mathrm{C}^{+}$and $\mathrm{CO}$, proposed by Watson $^{9}$ to occur in the ISM.

\section{COMPUTATIONAL METHOD}

Electronic structure calculations were made with the GAUSSIAN 94 program $^{28}$ at the CISD level (configuration interaction including all single and double excitations from the $\mathrm{SCF}$ reference configuration) using initially the split-valence 
plus polarization basis set $6-31 \mathrm{G}^{* *}$ (six second-order (5 $d$-type plus $1 s$-type) Gaussians for each heavy atom and three $p$-type for hydrogen) for $\mathrm{HCO}^{+}$and $\mathrm{HOC}^{+}$, and the basis set 6-31G* (six second-order Gaussians for each heavy atom) for $\mathrm{CO}$ and $\mathrm{C}_{2} \mathrm{O}^{+}$. This computational level is designated as CISD/6-31G** (or CISD/6-31G* if no $\mathrm{H}$ atoms present). Molecular geometries were optimized at this level using analytic gradients, while vibrational frequencies for stationary points were calculated from finite differences of analytic gradients. The energies of a number of possible structures for transition states (saddle points) and intermediates (local minima) for the $\mathrm{C}_{2} \mathrm{O}^{+}$adduct as formed in the isotope exchange reaction between $\mathrm{C}^{+}$and $\mathrm{CO}$ were computed at their CISD/6-31G* optimized geometries using the higher computational level $\operatorname{QCISD}(\mathrm{T}) / 6-311 \mathrm{G}(2 d f) / /$ CISD/6-31G*. These letters designate quadratic configuration interaction with single, double, and triple electronic excitations, with a triple-zeta basis set augmented by two sets of $d$-type and one set of $f$-type polarization functions.

Using the computed molecular structures and vibrational frequencies we next calculate the reduced partition function ratio $Q\left({ }^{13} \mathrm{C}\right) / Q\left({ }^{12} \mathrm{C}\right)$ for the ${ }^{13} \mathrm{C}$ and ${ }^{12} \mathrm{C}$ isotopic species of a given molecule. (Calculating the ratios of the molecular partition functions for isotopic species implicitly assumes invocation of the Teller-Redlich product rule, with the consequence that the molecular structural information contained in moments of inertia cancels, leaving the reduced ratios dependent only on isotopic changes in harmonic vibrational frequencies.) The reduced partition function ratio is defined as the ratio of the actual partition functions multiplied by the factor $\left[m\left({ }^{13} \mathrm{C}\right) / m\left({ }^{12} \mathrm{C}\right)\right]^{3 / 2 n}$, where $n$ is the number of carbon atoms exchanged; for $n$ of 1 this mass factor equals 1.128 005. (For reactions in which ${ }^{18} \mathrm{O}$ replaces ${ }^{16} \mathrm{O}$ there is similar factor of $\left[m\left({ }^{18} \mathrm{O}\right) / m\left({ }^{16} \mathrm{O}\right)\right]^{3 / 2}=1.193728$.) Thus defined, the reduced partition function ratio for exothermic exchange reactions approaches plus infinity as the temperature $T$ approaches zero, but unity as $T$ approached infinity. To obtain these ratios we calculated the molecular partition functions assuming ideal gas behavior for a range of temperatures from $T=10$ to $T=1000 \mathrm{~K}$. All vibrations are assumed to be harmonic and all rotations classical (hightemperature limit). The equilibrium constant $K_{\text {eq }}$ expressed in terms of thermodynamic activities $\underline{a}$

$$
K_{\mathrm{eq}}=\left[a\left({ }^{12} \mathrm{~A}\right) a\left({ }^{13} \mathrm{~B}\right)\right] /\left[a\left({ }^{13} \mathrm{~A}\right) a\left({ }^{12} \mathrm{~B}\right)\right]
$$

for a generic isotope exchange reaction

$$
{ }^{13} \mathrm{~A}+{ }^{12} \mathrm{~B} \rightarrow{ }^{12} \mathrm{~A}+{ }^{13} \mathrm{~B}
$$

between species $\mathrm{A}$ and $\mathrm{B}$ is then given simply by the ratio of the reduced partition function ratio for species $B$ to that for species A.

Fractionation is often expressed ${ }^{2}$ in terms of $\delta\left({ }^{13} \mathrm{C}\right)$ values which are defined for ${ }^{13} \mathrm{C},{ }^{12} \mathrm{C}$ mixtures by

$$
\delta\left({ }^{13} \mathrm{C}\right)=\left\{\left[\left({ }^{13} \mathrm{C} /{ }^{12} \mathrm{C}\right)_{\mathrm{spl}}-\left({ }^{13} \mathrm{C} /{ }^{12} \mathrm{C}\right)_{\mathrm{std}}\right] /\left({ }^{13} \mathrm{C} /{ }^{12} \mathrm{C}\right)_{\mathrm{std}}\right\} \times 10^{3},
$$

where "spl" denotes the sample and "std" the reference standard. The PDB-Chicago standard, ${ }^{12}$ based on belemnite fossils of the Peedee, SC, formation, has a value of
TABLE I. Zero-point energies, rotational constants, and vibrational constants.

\begin{tabular}{lccc}
\hline \hline Species & ZPE & $\vartheta_{\text {rot }}{ }^{\mathrm{b}}$ & $\vartheta_{\text {vib }}{ }^{\mathrm{a}}$ \\
\hline $\mathrm{CO}$ & 1628.5 & 2.74 & 3257 \\
${ }^{13} \mathrm{CO}$ & 1592.5 & 2.62 & 3185 \\
$\mathrm{C}^{18} \mathrm{O}$ & 1589.5 & 2.61 & 3179 \\
${ }^{13} \mathrm{C}^{18} \mathrm{O}$ & 1552.0 & 2.49 & $1271(\pi), 3332(\sigma), 4812(\sigma)$ \\
$\mathrm{HCO}^{+}$ & 5343.0 & 2.13 & $1259(\pi), 3280(\sigma), 4776(\sigma)$ \\
$\mathrm{H}^{13} \mathrm{CO}^{+}$ & 5287.0 & 2.07 & $1268(\pi), 3252(\sigma), 4805(\sigma)$ \\
$\mathrm{HC}^{18} \mathrm{O}^{+}$ & 5296.5 & 2.04 & $1256(\pi), 3197(\sigma), 4770(\sigma)$ \\
$\mathrm{H}^{13} \mathrm{C}^{18} \mathrm{O}^{+}$ & 5239.5 & 1.98 & $1017(\pi), 2904(\sigma), 3972(\sigma)$ \\
$\mathrm{DCO}^{+}$ & 4455.0 & 1.72 & $1002(\pi), 2894(\sigma), 3893(\sigma)$ \\
$\mathrm{D}^{13} \mathrm{CO}^{+}$ & 4395.5 & 1.69 & $1013(\pi), 2856(\sigma), 3933(\sigma)$ \\
$\mathrm{DC}^{18} \mathrm{O}^{+}$ & 4407.5 & 1.65 & $998(\pi), 2844(\sigma), 3855(\sigma)$ \\
$\mathrm{D}^{13} \mathrm{C}^{18} \mathrm{O}^{+}$ & 4347.5 & 1.61 & $95(\pi), 2922(\sigma), 5159(\sigma)$ \\
$\mathrm{HOC}^{+}$ & 4135.5 & 2.13 & $95(\pi), 2856(\sigma), 5158(\sigma)$ \\
$\mathrm{HO}^{13} \mathrm{C}^{+}$ & 4102.0 & 2.04 & $94(\pi), 2861(\sigma), 5136(\sigma)$ \\
$\mathrm{H}^{18} \mathrm{OC}^{+}$ & 4092.5 & 2.06 & $94(\pi), 2793(\sigma), 5135(\sigma)$ \\
$\mathrm{H}^{18} \mathrm{O}^{13} \mathrm{C}^{+}$ & 4058.0 & 1.97 & $69(\pi), 2814(\sigma), 3855(\sigma)$ \\
$\mathrm{DOC}^{+}$ & 3403.5 & 1.81 & $69(\pi), 2752(\sigma), 3849(\sigma)$ \\
$\mathrm{DO}^{13} \mathrm{C}^{+}$ & 3369.5 & 1.74 & $69(\pi), 2775(\sigma), 3806(\sigma)$ \\
$\mathrm{D}^{18} \mathrm{OC}^{+}$ & 3359.5 & 1.77 & $69(\pi), 2711(\sigma), 3801(\sigma)$ \\
$\mathrm{D}^{18} \mathrm{O}^{13} \mathrm{C}^{+}$ & 3325.0 & 1.69 & \\
\hline \hline
\end{tabular}

a Zero-point energy in $\mathrm{K}$ computed at optimized CISD/6-31G** level.

${ }^{\mathrm{b}}$ Rotational constants in $\mathrm{K}$ computed at optimized CISD/6-31G** level.

${ }^{\mathrm{c}}$ Vibrational constants in $\mathrm{K}$ computed at optimized CISD/6-31G** level.

$\left({ }^{13} \mathrm{C} /{ }^{12} \mathrm{C}\right)_{\text {std }}=0.01124$, corresponding to which the ${ }^{12} \mathrm{C} /{ }^{13} \mathrm{C}$ ratio is 88.968 and the atom fraction of ${ }^{13} \mathrm{C}$ is 0.01112 . Taking the activity for a given isotopic species to be proportional to its atomic concentration, an equilibrium constant may be rewritten as

$K_{\text {eq }}=\left({ }^{13} \mathrm{C} /{ }^{12} \mathrm{C}\right)_{\mathrm{B}} /\left({ }^{13} \mathrm{C} /{ }^{12} \mathrm{C}\right)_{\mathrm{A}}=\left[1+10^{-3} \delta(\mathrm{B})\right] /\left[1+10^{-3} \delta(\mathrm{A})\right]$,

where $\delta(\mathrm{B})$ and $\delta(\mathrm{A})$ denote the $\delta\left({ }^{13} \mathrm{C}\right)$ values for the ${ }^{13} \mathrm{C}$ containing product and reactant species, respectively. Note that the reference ratio $\left({ }^{13} \mathrm{C} /{ }^{12} \mathrm{C}\right)_{\text {std }}$ in Eq. (3) does not appear in Eq. (4), and that $\delta(\mathrm{B})$ and $\delta(\mathrm{A})$ are not uniquely determined by the value of $K_{\text {eq }}$.

\section{RESULTS AND DISCUSSION}

\section{Zero-point energies, spectroscopic constants, and partition functions}

In Table I we list the computed zero-point energies in $\mathrm{K}$ together with computed rotational constants and harmonic vibrational frequencies, also expressed in $\mathrm{K}$, for the various isotopomers of $\mathrm{CO}, \mathrm{HCO}^{+}$, and $\mathrm{HOC}^{+}$. We have chosen to express these constants in temperature units rather than wave numbers as our applications are primarily statistical thermodynamic rather than spectroscopic. In Tables II, III, and IV we list as a function of temperature reduced partition function ratios $Q\left({ }^{13} \mathrm{C}\right) / Q\left({ }^{12} \mathrm{C}\right)$ for $\mathrm{CO}, \mathrm{HCO}^{+}$, and $\mathrm{HOC}^{+}$, respectively.

Equilibrium constants $K_{\text {eq }}$ as a function of temperature for isotope exchange reactions having the form of the generic reaction (2) are given by the quotient of the appropriate pair of reduced partition function ratios as given in Tables II-IV. If the species $\mathrm{A}$ is atomic carbon (charged or neutral), the 
TABLE II. Reduced partition function ratios ${ }^{\mathrm{a}, \mathrm{b}} Q\left({ }^{13} \mathrm{C}\right) / Q\left({ }^{12} \mathrm{C}\right)$ for $\mathrm{CO}$.

\begin{tabular}{rcccc}
\hline \hline$T(\mathrm{~K})$ & ${ }^{13} \mathrm{CO} / \mathrm{CO}$ & ${ }^{13} \mathrm{C}^{18} \mathrm{O} / \mathrm{C}^{18} \mathrm{O}$ & ${ }^{13} \mathrm{CO} / \mathrm{C}^{18} \mathrm{O}$ & ${ }^{13} \mathrm{C}^{18} \mathrm{O} / \mathrm{CO}$ \\
\hline 10 & 36.90 & 40.41 & 0.739 & 2016 \\
25 & 4.178 & 4.329 & 0.887 & 20.38 \\
50 & 2.021 & 2.056 & 0.942 & 4.407 \\
100 & 1.406 & 1.417 & 0.972 & 2.049 \\
200 & 1.172 & 1.176 & 0.987 & 1.400 \\
300 & 1.103 & 1.106 & 0.992 & 1.230 \\
400 & 1.071 & 1.072 & 0.994 & 1.154 \\
600 & 1.039 & 1.040 & 0.997 & 1.084 \\
800 & 1.025 & 1.025 & 0.998 & 1.052 \\
1000 & 1.017 & 1.017 & 0.999 & 1.036 \\
\hline
\end{tabular}

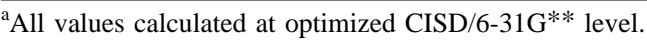

${ }^{\mathrm{b}}$ The reduction factors are $\left[m\left({ }^{13} \mathrm{C}\right) / m\left({ }^{12} \mathrm{C}\right)\right]^{3 / 2}=1.128005$ and $\left[m\left({ }^{18} \mathrm{O}\right) / m\left({ }^{16} \mathrm{O}\right)\right]^{3 / 2}=1.193728$.

equilibrium constants are given directly by the reduced partition function ratio for species $\mathrm{B}$ as that for the atomic species is taken to be unity. Values of $\delta\left({ }^{13} \mathrm{C}\right)$ for any exchange reaction may be obtained given some assumption about the relationship of $\delta$ for species B to that for species A.

\section{$\mathrm{HCO}^{+} / \mathrm{CO}$}

In Table $\mathrm{V}$ we list $K_{\text {eq }}$ values for isotope exchange reactions involving the species $\mathrm{HCO}^{+}$and $\mathrm{CO}$, displayed with their $\Delta \mathrm{ZPE}$ values in $\mathrm{K}$, the latter corresponding to $\Delta U$ values at $0 \mathrm{~K}$. The first two are

${ }^{13} \mathrm{CO}+\mathrm{HCO}^{+} \rightarrow \mathrm{H}^{13} \mathrm{CO}^{+}+\mathrm{CO} \quad \Delta \mathrm{ZPE}=-20.0 \mathrm{~K}$,

${ }^{13} \mathrm{C}^{18} \mathrm{O}+\mathrm{HC}^{18} \mathrm{O}^{+} \rightarrow \mathrm{H}^{13} \mathrm{C}^{18} \mathrm{O}^{+}+\mathrm{C}^{18} \mathrm{O} \quad \Delta \mathrm{ZPE}=-19.5 \mathrm{~K}$.

(Unlabeled atoms are understood to represent the most abundant isotopes, namely ${ }^{1} \mathrm{H},{ }^{12} \mathrm{C}$, and ${ }^{16} \mathrm{O}$.) Other isotopic variants of the above exchange reactions include simple proton transfers which are in effect exchanges of two isotopes, namely

$$
\begin{aligned}
& { }^{13} \mathrm{CO}+\mathrm{HC}^{18} \mathrm{O}^{+} \rightarrow \mathrm{H}^{13} \mathrm{CO}^{+}+\mathrm{C}^{18} \mathrm{O} \quad \Delta \mathrm{ZPE}=-12.5 \mathrm{~K}, \\
& { }^{13} \mathrm{C}^{18} \mathrm{O}+\mathrm{HCO}^{+} \rightarrow \mathrm{H}^{13} \mathrm{C}^{18} \mathrm{O}^{+}+\mathrm{CO} \quad \Delta \mathrm{ZPE}=-27.0 \mathrm{~K},
\end{aligned}
$$

TABLE III. Reduced partition function ratios ${ }^{\mathrm{a}, \mathrm{b}} Q\left({ }^{13} \mathrm{C}\right) / Q\left({ }^{12} \mathrm{C}\right)$ for $\mathrm{HCO}^{+}$ and $\mathrm{HOC}^{+}$.

\begin{tabular}{rcccc}
\hline \hline$T(\mathrm{~K})$ & $\begin{array}{c}\mathrm{H}^{13} \mathrm{CO}^{+} / \\
\mathrm{HCO}^{+}\end{array}$ & $\begin{array}{c}\mathrm{H}^{13} \mathrm{C}^{18} \mathrm{O}^{+} / \\
\mathrm{HC}^{18} \mathrm{O}^{+}\end{array}$ & $\begin{array}{c}\mathrm{HO}^{13} \mathrm{C}^{+} / \\
\mathrm{HOC}^{+}\end{array}$ & $\begin{array}{c}\mathrm{H}^{18} \mathrm{O}^{13} \mathrm{C}^{+} / \\
\mathrm{H}^{18} \mathrm{OC}^{+}\end{array}$ \\
\hline 10 & 246.8 & 268.6 & 27.76 & 29.99 \\
25 & 8.798 & 9.131 & 3.718 & 3.832 \\
50 & 2.905 & 2.958 & 1.902 & 1.930 \\
100 & 1.669 & 1.683 & 1.360 & 1.369 \\
200 & 1.266 & 1.270 & 1.150 & 1.153 \\
300 & 1.155 & 1.158 & 1.088 & 1.089 \\
400 & 1.105 & 1.106 & 1.058 & 1.058 \\
600 & 1.058 & 1.059 & 1.029 & 1.030 \\
800 & 1.037 & 1.037 & 1.016 & 1.016 \\
1000 & 1.026 & 1.026 & 1.010 & 1.010 \\
\hline \hline
\end{tabular}

${ }^{\mathrm{a}}$ All values calculated at optimized CISD/6-31G** level.

${ }^{\mathrm{b}}$ The reduction factor is $\left[m\left({ }^{13} \mathrm{C}\right) / m\left({ }^{12} \mathrm{C}\right)\right]^{3 / 2}=1.128005$.
TABLE IV. Reduced partition function ratios ${ }^{\mathrm{a}, \mathrm{b}} Q\left({ }^{13} \mathrm{C}\right) / Q\left({ }^{12} \mathrm{C}\right)$ for $\mathrm{DCO}^{+}$ and $\mathrm{DOC}^{+}$

\begin{tabular}{rcccc}
\hline \hline$T(\mathrm{~K})$ & $\begin{array}{c}\mathrm{D}^{13} \mathrm{CO}^{+} / \\
\mathrm{DCO}^{+}\end{array}$ & $\begin{array}{c}\mathrm{D}^{13} \mathrm{C}^{18} \mathrm{O}^{+} / \\
\mathrm{DC}^{18} \mathrm{O}^{+}\end{array}$ & $\begin{array}{c}\mathrm{DO}^{13} \mathrm{C}^{+} / \\
\mathrm{DOC}^{+}\end{array}$ & $\begin{array}{c}\mathrm{D}^{18} \mathrm{O}^{13} \mathrm{C}^{+} / \\
\mathrm{D}^{18} \mathrm{OC}^{+}\end{array}$ \\
\hline 10 & 360.8 & 395.9 & 28.51 & 30.68 \\
25 & 10.21 & 10.59 & 3.751 & 3.859 \\
50 & 3.113 & 3.168 & 1.907 & 1.933 \\
100 & 1.718 & 1.733 & 1.359 & 1.369 \\
200 & 1.278 & 1.282 & 1.148 & 1.150 \\
300 & 1.160 & 1.163 & 1.085 & 1.086 \\
400 & 1.108 & 1.109 & 1.055 & 1.055 \\
600 & 1.060 & 1.060 & 1.026 & 1.026 \\
800 & 1.038 & 1.038 & 1.013 & 1.013 \\
1000 & 1.026 & 1.026 & 1.007 & 1.006 \\
\hline \hline
\end{tabular}

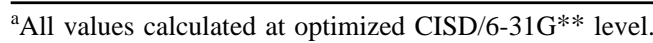

${ }^{\mathrm{b}}$ The reduction factor is $\left[m\left({ }^{13} \mathrm{C}\right) / m\left({ }^{12} \mathrm{C}\right)\right]^{3 / 2}=1.128005$.

as well as reactions which are not simple proton transfers but instead involve breaking and reforming $\mathrm{CO}$ bonds to achieve exchange of a single isotope, namely,

$$
\begin{aligned}
& { }^{13} \mathrm{CO}+\mathrm{HC}^{18} \mathrm{O}^{+} \rightarrow \mathrm{H}^{13} \mathrm{C}^{18} \mathrm{O}^{+}+\mathrm{CO} \quad \Delta \mathrm{ZPE}=-21.0 \mathrm{~K}, \\
& { }^{13} \mathrm{C}^{18} \mathrm{O}+\mathrm{HCO}^{+} \rightarrow \mathrm{H}^{13} \mathrm{CO}^{+}+\mathrm{C}^{18} \mathrm{O} \quad \Delta \mathrm{ZPE}=-18.5 \mathrm{~K} .
\end{aligned}
$$

Equilibrium constants for reactions (5), (6), (9), and (10) differ negligibly as their $\triangle \mathrm{ZPE}$ values differ negligibly. Reaction (7), which involves one heavy isotope in each reactant and product species, is the least exothermic of the set of six reactions, while reaction (8), which concentrates both heavy isotopes in the product species $\mathrm{H}^{13} \mathrm{C}^{18} \mathrm{O}^{+}$, is the most exothermic. [The equilibrium constants for all of the above reactions except Eqs. (7) and (8) are obtained as quotients of reduced partition function ratios from Tables III and IV; the mixed $\mathrm{CO}$ ratios needed for Eqs. (7) and (8) are included in Table II, but the mixed ratios for $\mathrm{HCO}^{+}$are not tabulated.] The $\mathrm{HCO}^{+} / \mathrm{CO}$ exchange reactions may be exothermic without having ${ }^{13} \mathrm{CO}$ or ${ }^{13} \mathrm{C}^{18} \mathrm{O}$ as a reactant; subtracting Eq. (7) from Eqs. (9) or (10) from Eq. (8) yields

$$
\mathrm{C}^{18} \mathrm{O}+\mathrm{H}^{13} \mathrm{CO}^{+} \rightarrow \mathrm{H}^{13} \mathrm{C}^{18} \mathrm{O}^{+}+\mathrm{CO} \quad \Delta \mathrm{ZPE}=-8.5 \mathrm{~K} .
$$

Another exothermic variant is obtained by subtracting Eq. (7) from Eqs. (10) or (9) from Eq. (8), yielding

$$
{ }^{13} \mathrm{C}^{18} \mathrm{O}+\mathrm{HCO}^{+} \rightarrow \mathrm{HC}^{18} \mathrm{O}^{+}+{ }^{13} \mathrm{CO} \quad \Delta \mathrm{ZPE}=-6.0 \mathrm{~K} \text {. }
$$

We do not tabulate the $K_{\text {eq }}$ values for the slightly exothermic reactions (11) and (12), as they may be readily obtained by combining tabulated values.

While at temperatures of say, 10 to $50 \mathrm{~K}, \Delta G^{\circ}$ values for isotope exchange reactions are approximated well by zero-point energy differences ( $\triangle \mathrm{ZPE}$ 's), so that equilibrium constants are approximately $\exp (-\Delta \mathrm{ZPE} / \mathrm{RT})$, at temperatures of several hundred $\mathrm{K}$ the $\Delta G^{\circ}$ values are considerably smaller in magnitude than the $\triangle$ ZPE's. For reaction (5) $\Delta \mathrm{ZPE}$ is $-158 \mathrm{~J} \mathrm{~mol}^{-1}$, while $\Delta G^{\circ}$ at $500 \mathrm{~K}$ is $-96 \mathrm{~J} \mathrm{~mol}^{-1} ; K_{\mathrm{eq}}$ is 1.023 vs 1.039 if approximated as $\exp (-\Delta \mathrm{ZPE} / \mathrm{RT})$. The difference appears slight, but the deviations from unity, to which equilibrium fractionations are closely related, are significantly different. 
TABLE V. Isotope exchange equilibrium constants for $\mathrm{HCO}^{+} / \mathrm{CO}$ reactions. ${ }^{\mathrm{a}}$

\begin{tabular}{|c|c|c|c|c|c|c|}
\hline$T(\mathrm{~K})$ & $\begin{array}{l}\mathrm{HCO}^{+} /{ }^{13} \mathrm{CO} \\
\mathrm{H}^{13} \mathrm{CO}^{+} / \mathrm{CO}\end{array}$ & $\begin{array}{l}\mathrm{HC}^{18} \mathrm{O}^{+} /{ }^{13} \mathrm{C}^{18} \mathrm{O} \\
\mathrm{H}^{13} \mathrm{C}^{18} \mathrm{O}^{+} / \mathrm{C}^{18} \mathrm{O}\end{array}$ & $\begin{array}{l}\mathrm{HC}^{18} \mathrm{O}^{+} /{ }^{13} \mathrm{CO} \\
\mathrm{H}^{13} \mathrm{CO}^{+} / \mathrm{C}^{18} \mathrm{O}\end{array}$ & $\begin{array}{l}\mathrm{HCO}^{+} /{ }^{13} \mathrm{C}^{18} \mathrm{O} \\
\mathrm{H}^{13} \mathrm{C}^{18} \mathrm{O}^{+} / \mathrm{CO}\end{array}$ & $\begin{array}{l}\mathrm{HC}^{18} \mathrm{O}^{+} /{ }^{13} \mathrm{CO} \\
\mathrm{H}^{13} \mathrm{C}^{18} \mathrm{O}^{+} / \mathrm{CO}\end{array}$ & $\begin{array}{l}\mathrm{HCO}^{+} /{ }^{13} \mathrm{C}^{18} \mathrm{O} \\
\mathrm{H}^{13} \mathrm{CO}^{+} / \mathrm{C}^{18} \mathrm{O}\end{array}$ \\
\hline 10 & 6.690 & 6.648 & 3.327 & 13.37 & 7.281 & 6.109 \\
\hline 25 & 2.106 & 2.109 & 1.605 & 2.768 & 2.186 & 2.032 \\
\hline 50 & 1.438 & 1.438 & 1.254 & 1.643 & 1.464 & 1.413 \\
\hline 100 & 1.187 & 1.188 & 1.111 & 1.266 & 1.198 & 1.178 \\
\hline 150 & 1.114 & 1.115 & 1.070 & 1.160 & 1.120 & 1.109 \\
\hline 200 & 1.080 & 1.080 & 1.049 & 1.111 & 1.084 & 1.076 \\
\hline 300 & 1.047 & 1.047 & 1.029 & 1.065 & 1.049 & 1.045 \\
\hline 400 & 1.032 & 1.032 & 1.019 & 1.044 & 1.033 & 1.030 \\
\hline 500 & 1.023 & 1.023 & 1.014 & 1.032 & 1.024 & 1.022 \\
\hline 600 & 1.018 & 1.018 & 1.011 & 1.025 & 1.019 & 1.018 \\
\hline 700 & 1.014 & 1.014 & 1.009 & 1.020 & 1.015 & 1.014 \\
\hline 800 & 1.012 & 1.012 & 1.007 & 1.016 & 1.012 & 1.012 \\
\hline 900 & 1.010 & 1.010 & 1.006 & 1.014 & 1.010 & 1.010 \\
\hline 1000 & 1.008 & 1.008 & 1.005 & 1.012 & 1.009 & 1.008 \\
\hline$\Delta \mathrm{ZPE}^{\mathrm{b}}$ & -20.0 & -19.5 & -12.5 & -27.0 & -21.0 & -18.5 \\
\hline
\end{tabular}

${ }^{a}$ The first line denotes reactants, the second denotes products. The reactions are given by Eqs. (5)-(10).

${ }^{\mathrm{b}}$ Zero-point energy changes in $\mathrm{K}$.

In their laboratory SIFT (selected ion flow tube) studies of the reactions of $\mathrm{HCO}^{+}$with $\mathrm{CO}$, Smith and Adams ${ }^{10}$ obtained $K_{\text {eq }}$ values for reaction (5) of $1.17,1.07,1.04$, and 1.00 for $T=80,200,300$, and $510 \mathrm{~K}$, respectively, in reasonable agreement with our computed values of 1.187, 1.080, 1.047 , and 1.023 for $T=100,200,300$, and $500 \mathrm{~K}$, respectively. They also noted that since reactions such as Eqs. (7) and (9) involve the same reactants [as does also the endothermic reverse of Eq. (12)], single reversible reactions cannot be cleanly studied for these mixed $\left({ }^{12} \mathrm{C},{ }^{13} \mathrm{C},{ }^{16} \mathrm{O},{ }^{18} \mathrm{O}\right)$ systems. Similarly, the endothermic reverses of Eqs. (8), (9), and (11) have identical reactants. They do report that the appearance of channel (9) is about $10 \%$ of that for the less exothermic (by almost a factor of 2) channel (7), but as noted above, (7) is a simple proton transfer, while (9) involves breaking and reforming the $\mathrm{CO}$ bonds, which undoubtedly accounts for the greater importance of Eq. (7) compared to Eq. (9).

A striking result of these SIFT studies ${ }^{10}$ of the $\mathrm{HCO}^{+} / \mathrm{CO}$ exchange reaction is the observed decrease in both the forward and reverse rate constants as the temperature is increased from 80 to $510 \mathrm{~K}$, a result strongly suggestive of a reaction pathway involving exothermic complex formation. We have located a centrosymmetric linear saddle point with connectivity $\mathrm{OCHCO}$ on the five-atom potential energy surface for $\mathrm{CO}+\mathrm{HCO}^{+}$. At the optimized CISD/6-31G** level the $\mathrm{CO}$ and $\mathrm{CH}$ separations are 1.115 and $1.382 \AA$, respectively, with the only imaginary vibrational wave number being $1039 i \mathrm{~cm}^{-1}$ for an antisymmetric $\sigma_{u}$ stretching mode. The energy of this possible transition state structure for proton transfer between $\mathrm{HCO}^{+}$and $\mathrm{CO}$, and hence for ${ }^{13} \mathrm{C} /{ }^{12} \mathrm{C}$ isotope exchange, is $-46.0 \mathrm{~kJ} \mathrm{~mol}{ }^{-1}$ relative to that of the reactants at the higher QCISD(T)/6-311 $g(2 d f) / /$ ISD/6-31G** level; the zeropoint energy change for formation of this transition state from $\mathrm{HCO}^{+}$and ${ }^{13} \mathrm{CO}$ is $-4.1 \mathrm{~kJ} \mathrm{~mol}^{-1}$ at the CISD/6-31G** level, giving a total exothermicity of $-50.1 \mathrm{~kJ} \mathrm{~mol}^{-1}$. The imaginary $\sigma_{u}$ vibrational frequency in turn implies that a linear structure with unequal $\mathrm{CH}$ separa- tions lies at a still lower energy, thus supporting the suggestion of exothermic complex formation at least for those $\mathrm{HCO}^{+} / \mathrm{CO}$ exchanges which may occur by proton transfer rather than by breaking and reforming $\mathrm{CO}$ bonds. In the next section we discuss in greater detail complex formation and the observation ${ }^{10}$ of similar anti-Arrhenius behavior in the reaction of $\mathrm{C}^{+}$with $\mathrm{CO}$.

Equilibrium constants for the deuterium counterpart of Eq. (5), namely

$$
{ }^{13} \mathrm{CO}+\mathrm{DCO}^{+} \rightarrow \mathrm{D}^{13} \mathrm{CO}^{+}+\mathrm{CO} \quad \Delta \mathrm{ZPE}=-23.0 \mathrm{~K}
$$

are given in Table VI. The values are slightly higher than their proton counterparts due to the slightly higher exothermicity of the deuterium reaction. Values for the ${ }^{18} \mathrm{O}$ variant of Eq. (13) are not sufficiently different from those for Eq. (13) to warrant tabulation.

TABLE VI. Isotope exchange equilibrium constants for $\mathrm{DCO}^{+} / \mathrm{CO}$, $\mathrm{HOC}^{+} / \mathrm{CO}$, and $\mathrm{DOC}^{+} / \mathrm{CO}$ reactions. ${ }^{\mathrm{a}}$

\begin{tabular}{rccc}
\hline \hline$T(\mathrm{~K})$ & $\begin{array}{c}\mathrm{DCO}^{+} /{ }^{13} \mathrm{CO} \\
\mathrm{D}^{13} \mathrm{CO}^{+} / \mathrm{CO}\end{array}$ & $\begin{array}{c}\mathrm{HO}^{13} \mathrm{C}^{+} / \mathrm{CO} \\
\mathrm{HOC}^{+} /{ }^{13} \mathrm{CO}\end{array}$ & $\begin{array}{c}\mathrm{DO}^{13} \mathrm{C}^{+} / \mathrm{CO} \\
\mathrm{DOC}^{+} /{ }^{13} \mathrm{CO}\end{array}$ \\
\hline 10 & 9.780 & 1.329 & 1.294 \\
25 & 2.445 & 1.124 & 1.114 \\
50 & 1.540 & 1.062 & 1.060 \\
100 & 1.222 & 1.034 & 1.034 \\
150 & 1.132 & 1.024 & 1.026 \\
200 & 1.090 & 1.019 & 1.021 \\
300 & 1.052 & 1.015 & 1.017 \\
400 & 1.035 & 1.012 & 1.015 \\
500 & 1.025 & 1.011 & 1.014 \\
600 & 1.019 & 1.010 & 1.013 \\
700 & 1.016 & 1.009 & 1.012 \\
800 & 1.013 & 1.008 & 1.011 \\
900 & 1.010 & 1.008 & 1.010 \\
1000 & 1.009 & 1.007 & 1.010 \\
$\Delta \mathrm{ZPE}^{\mathrm{b}}$ & -23.0 & -2.5 & -2.0 \\
\hline
\end{tabular}

The first line denotes reactants, the second denotes products. The reactions are given by Eqs. (13)-(15).

bero-point energy changes in $\mathrm{K}$. 


\section{$\mathrm{HOC}^{+} / \mathrm{CO}$}

An important isomer of $\mathrm{HCO}^{+}$is $\mathrm{HOC}^{+}$, the analog of hydrogen isocyanide. Measurements of the millimeter-wave transitions of $\mathrm{HOC}^{+}$in dense molecular clouds have recently been made ${ }^{29}$ and used to obtain $\left[\mathrm{HCO}^{+}\right] /\left[\mathrm{HOC}^{+}\right]$ratios. At the optimized CISD/6-31G** level this isomer lies higher in electronic energy by $150.9 \mathrm{~kJ} \mathrm{~mol}^{-1}$ or $18,150 \mathrm{~K}$ than the more stable $\mathrm{HCO}^{+}$isomer. The zero-point energy difference lowers this by $1208 \mathrm{~K}$ for ${ }^{12} \mathrm{C}$ and by $1185 \mathrm{~K}$ for ${ }^{13} \mathrm{C}$ (Table I). Table VI lists values of the equilibrium constant for the exchange reaction

$$
\mathrm{CO}+\mathrm{HO}^{13} \mathrm{C}^{+} \rightarrow \mathrm{HOC}^{+}+{ }^{13} \mathrm{CO} \quad \Delta \mathrm{ZPE}=-2.5 \mathrm{~K}
$$

and its deuterium counterpart

$$
\mathrm{CO}+\mathrm{DO}^{13} \mathrm{C}^{+} \rightarrow \mathrm{DOC}^{+}+{ }^{13} \mathrm{CO} \quad \Delta \mathrm{ZPE}=-2.0 \mathrm{~K} .
$$

The exothermicities are small, but note that the direction of the reactions is the opposite of that for $\mathrm{HCO}^{+} / \mathrm{CO}$ exchange, namely that there is a slight preference for ${ }^{13} \mathrm{C}$ being in $\mathrm{CO}$ rather than in $\mathrm{HOC}^{+}$.

\section{The reaction of $\mathrm{C}^{+}$and $\mathrm{CO}$}

Watson ${ }^{9}$ proposed that significant chemical fractionation of $\mathrm{C}$ isotopes in the ISM might occur via the reaction

$$
{ }^{13} \mathrm{C}^{+}+\mathrm{CO} \rightarrow \mathrm{C}^{+}+{ }^{13} \mathrm{CO},
$$

if sufficiently large amounts of $\mathrm{C}^{+}$were present. Given the significance of this proposal we have considered possible pathways for this isotope exchange. First, it may well be that such exchanges, assuming that they occur in the ISM, take place indirectly via exothermic reaction pairs such as

$$
\begin{aligned}
& \mathrm{C}^{+}+\mathrm{OH} \rightarrow \mathrm{CO}+\mathrm{H}^{+}, \\
& \mathrm{He}^{+}+\mathrm{CO} \rightarrow \mathrm{C}^{+}+\mathrm{O}+\mathrm{He},
\end{aligned}
$$

just as exchange between $\mathrm{CO}$ and $\mathrm{HCO}^{+}$may occur via the exothermic reaction pair

$$
\begin{aligned}
& \mathrm{H}_{3}{ }^{+}+\mathrm{CO} \rightarrow \mathrm{H}_{2}+\mathrm{HCO}^{+}, \\
& \mathrm{HCO}^{+}+e^{-} \rightarrow \mathrm{H}+\mathrm{CO} .
\end{aligned}
$$

Reaction (19) presumably proceeds through the adduct $\mathrm{H}_{2} \cdots \mathrm{HCO}^{+}$, which has been studied ${ }^{30}$ by ir spectroscopy; the more stable ${ }^{30}$ protonated formaldehyde isomer $\mathrm{H}_{2} \mathrm{COH}^{+}$ does not lead to $\mathrm{HCO}^{+}$production. Different rate constants for different $\mathrm{C}$ isotopes in a reaction pair can lead to chemical fractionation, although such differences are expected to be small for exothermic pairs such as Eqs. (19) and (20). Alternatively reaction (16) may proceed directly, via a $\mathrm{C}_{2} \mathrm{O}^{+}$ adduct, as is presumably the case in the laboratory SIFT studies of Smith and Adams. ${ }^{10}$ They found $K_{\text {eq }}$ values, defined as the ratio $k_{f} / k_{r}$ of forward and reverse rate constants, for reaction (16) to be 1.66, 1.20, 1.14, and 1.04 at $T=80$, 200,300 , and $510 \mathrm{~K}$, respectively; from the temperature dependence of $K_{\text {eq }}$ they extracted a $\Delta E$ value of $-40 \pm 6 \mathrm{~K}$. Our calculated equilibrium constants for Eq. (16) are equal to the reduced partition function ratios for $\mathrm{CO}$ as given in Table II; the values are 1.406, 1.172, 1.103, and 1.052 for temperatures of $100,200,300$, and $500 \mathrm{~K}$, respectively. A striking result was their finding that the individual rate constants decreased with rising temperature, $k_{f}$ by a factor of 2.6 as $T$ increased from 80 to $510 \mathrm{~K}$, and $k_{r}$ by a factor of 1.6 . They interpreted this anti-Arrhenius behavior as evidence for adduct formation, which is the aspect of this reaction we explore next.

There have been a number of computational quantum chemical studies of $\mathrm{C}_{2} \mathrm{O}^{+}$. First, $\mathrm{HF} / \mathrm{DZ}$ (double-zeta) structures with $C_{\infty v}$ symmetry have been reported ${ }^{31}$ for linear ${ }^{2} \Pi$ states with both $\mathrm{CCO}$ and $\mathrm{COC}$ connectivities, the latter with unequal $\mathrm{CO}$ bond lengths, as well as for a presumed linear saddle point structure with $D_{\infty h}$ symmetry. Results have also been reported at various higher levels of computation for the two linear ${ }^{2} \Pi$ states, ${ }^{32,33}$ for linear ${ }^{2} \Sigma^{-}$and ${ }^{4} \Sigma^{-}$states with CCO connectivity, ${ }^{34}$ and for a triangular $\left(C_{2 v}\right.$ symmetry) ${ }^{4} A_{2}$ transition state. ${ }^{34} \mathrm{~A}$ state should meet two requirements for it to serve as an intermediate for reaction (14), first, that the $2 \mathrm{C}$ atoms should occupy equivalent positions in the structure (thus excluding the linear $\mathrm{CCO}^{+}$forms and the noncentrosymmetric $\mathrm{COC}^{+}$form), and second, that the electronic state should be a spin doublet. The latter requirement follows from the spin state of $\mathrm{C}^{+}$being a doublet $\left({ }^{2} P\right)$ and that of $\mathrm{CO}$ a singlet, so that exchange proceeding through a quartet intermediate to doublet products would involve two curve crossings and thus be inefficient although not precluded. The only reported structure satisfying these requirements is the centrosymmetric $\mathrm{COC}^{+}$saddle point, ${ }^{31}$ with a $\mathrm{HF} / \mathrm{DZ}$ energy approximately $32 \mathrm{~kJ} \mathrm{~mol}^{-1}$ above that of the $\mathrm{C}^{+}$and $\mathrm{CO}$ reactants.

We have located a total of 9 stationary points, 5 corresponding to spin doublets and 4 to spin quartets, on the $\mathrm{C}_{2} \mathrm{O}^{+}$ surface at the CISD/6-31G* level. Vibrational frequencies were calculated at this level from finite differences of analytic first derivatives, and then the energies were recalculated at the higher $\operatorname{QCISD}(\mathrm{T}) / 6-311 \mathrm{G}(2 d f)$ level using the CISD/6-31G* geometries. The energies and structures are summarized in Tables VII and VIII, respectively. We first discuss the spin doublets as they may be derived from the ground states of $\mathrm{C}^{+}$and $\mathrm{CO}$. The lowest energy spin doublet is the previously reported ${ }^{31-33}$ linear ${ }^{2} \Pi$ state with connectivity $\mathrm{CCO}^{+}$. The CC distance is long $(1.600 \AA)$, the $\mathrm{CO}$ distance short $(1.094 \AA)$, so the structure clearly represents an adduct of $\mathrm{C}^{+}$and an only slightly perturbed $\mathrm{CO}$. The energy is $-250.7 \mathrm{~kJ} \mathrm{~mol}^{-1}$ relative to $\mathrm{C}^{+}+\mathrm{CO}$ at the QCISD(T)/6-311G(2df)//CISD/6-31G* level. However, this structure cannot account for the exchange of $\mathrm{C}$ atoms between $\mathrm{C}^{+}$and $\mathrm{CO}$. By contrast the linear ${ }^{2} \Pi$ state with connectivity $\mathrm{COC}^{+}$may, as it is associated with a symmetric double-well potential energy function. The ${ }^{2} \Pi_{g}$ state of the centrosymmetric $D_{\infty h}$ structure has an energy of $-84.4 \mathrm{~kJ} \mathrm{~mol}^{-1}$ relative to $\mathrm{C}^{+}+\mathrm{CO}$ at the $\mathrm{QCISD}(\mathrm{T}) /$ 6-311G(2df)//CISD/6-31G* level, and is unstable with respect to the antisymmetric stretching mode leading to the ${ }^{2} \Pi$ state of a noncentrosymmetric $C_{\infty v}$ structure having an energy of $-102.5 \mathrm{~kJ} \mathrm{~mol}^{-1}$. Figure 1 shows a schematic potential energy curve of the exothermic formation of this linear adduct; the relative energy values include zero-point energies at the CISD/6-31G* level as appropriate to the presence of one ${ }^{13} \mathrm{C}$ in the reaction. With this inclusion the $D_{\infty h}$ 
TABLE VII. Ab initio energies and energy differences ${ }^{\mathrm{a}}$ for the $\mathrm{C}_{2} \mathrm{O}^{+} / \mathrm{C}^{+}+\mathrm{CO}$ exchange reaction.

\begin{tabular}{|c|c|c|c|c|}
\hline Symmetry (Term) & CISD/6-31G* & $\operatorname{QCISD}(\mathrm{T}) / 6-311 \mathrm{G}(2 d f)$ & $\mathrm{ZPE}\left({ }^{12} \mathrm{C}\right)$ & ${ }^{b} \mathrm{ZPE}\left({ }^{13} \mathrm{C}\right)^{\mathrm{c}}$ \\
\hline$C_{\infty}\left({ }^{2} \Pi\right), \mathrm{CCO}^{+}$ & $\begin{array}{l}-150.42822 \\
(-168.4)\end{array}$ & $\begin{array}{l}-150.61051 \\
(-250.7)\end{array}$ & $\begin{aligned} & 0.00851 \\
(+ & 8.8)\end{aligned}$ & $\begin{aligned} & 0.00833,0.00847 \\
(+8.6, & +9.0)\end{aligned}$ \\
\hline$C_{\infty v}\left({ }^{2} \Pi\right), \mathrm{COC}^{+}$ & $\begin{array}{l}-150.38473 \\
(-54.3)\end{array}$ & $\begin{array}{l}-150.55405 \\
(-102.5)\end{array}$ & $\begin{aligned} & 0.00598 \\
&(+2.2)\end{aligned}$ & $\begin{aligned} & 0.00587,0.00596 \\
&(+2.2,+2.4)\end{aligned}$ \\
\hline$D_{\infty h}\left({ }^{2} \Pi_{g}\right), \mathrm{COC}^{+}$ & $\begin{array}{l}-150.37009 \\
(-15.8)\end{array}$ & $\begin{array}{l}-150.54716 \\
(-84.4)\end{array}$ & $\begin{aligned} & 0.00385 \\
&(-3.4)\end{aligned}$ & $\begin{array}{l}0.00379 \\
(-3.3)\end{array}$ \\
\hline$C_{2 v}\left({ }^{2} A_{1}\right)$ & $\begin{array}{l}-150.36371 \\
(+0.9)\end{array}$ & $\begin{array}{l}-150.54396 \\
(-76.0)\end{array}$ & $\begin{aligned} & 0.00598 \\
(+ & 2.2)\end{aligned}$ & $\begin{aligned} & 0.00590 \\
(+ & 2.3)\end{aligned}$ \\
\hline$C_{s}\left({ }^{2} A^{\prime}\right)$ & $\begin{array}{l}-150.35694 \\
(+18.6)\end{array}$ & $\begin{array}{l}-150.53737 \\
(-58.7)\end{array}$ & $\begin{array}{l}0.00501 \\
(-0.4)\end{array}$ & $\begin{array}{l}0.00499,0.00492 \\
(-0.1,-0.3)\end{array}$ \\
\hline$C_{\infty v}\left({ }^{4} \Sigma^{-}\right), \mathrm{CCO}^{+}$ & $\begin{array}{l}-150.43212 \\
(-178.7)\end{array}$ & $\begin{array}{l}-150.60198 \\
(-228.3)\end{array}$ & $\begin{array}{r}0.01042 \\
(+13.8)\end{array}$ & $\begin{array}{l}0.01022,0.01033 \\
(+13.6,+13.9)\end{array}$ \\
\hline$C_{s}\left({ }^{4} A^{\prime \prime}\right)$ & $\begin{array}{l}-150.30927 \\
(+143.8)\end{array}$ & $\begin{array}{l}-150.48396 \\
(+81.5)\end{array}$ & $\begin{array}{l}0.00745 \\
(+6.0)\end{array}$ & $\begin{array}{c}0.00732,0.00737 \\
(+6.0,+6.1)\end{array}$ \\
\hline$C_{2 v}\left({ }^{4} A_{2}\right)$ & $\begin{array}{l}-150.30849 \\
(+145.9)\end{array}$ & $\begin{array}{l}-150.48438 \\
(+80.4)\end{array}$ & $\begin{array}{c}0.01183 \\
(+17.5)\end{array}$ & $\begin{array}{l}0.01165 \\
(+17.4)\end{array}$ \\
\hline$D_{\infty h}\left({ }^{4} \Sigma_{u}^{-}\right), \mathrm{COC}^{+}$ & $\begin{array}{l}-150.26189 \\
(+268.2)\end{array}$ & $\begin{array}{l}-150.46500 \\
(+131.2)\end{array}$ & $\begin{array}{c}0.00776 \\
(+6.8)\end{array}$ & $\begin{array}{c}0.00766 \\
(+6.9)\end{array}$ \\
\hline $\mathrm{C}^{+}\left({ }^{2} \mathrm{P}\right)+\mathrm{CO}$ & $\begin{array}{c}-150.36406 \\
(0)\end{array}$ & $\begin{array}{l}-150.51501 \\
(0)\end{array}$ & $\begin{array}{l}0.00516 \\
(0)\end{array}$ & $\begin{array}{l}0.00504 \\
(0)\end{array}$ \\
\hline
\end{tabular}

anergies in hartrees and energy differences (in parentheses) in $\mathrm{kJ} \mathrm{mol}^{-1}$, all at optimized CISD/6-31G* geometries. The $D_{\infty h}\left({ }^{2} \Pi_{g}\right)$ and $C_{s}\left({ }^{2} A^{\prime}\right)$ structures are saddle points, the others local minima at this level.

${ }^{b}$ Zero-point energy of pure ${ }^{12} \mathrm{C}$ species.

'Zero-point energy of mixed ${ }^{13} \mathrm{C},{ }^{12} \mathrm{C}$ species; the first value for $C_{s}$ symmetry is for long bond to ${ }^{13} \mathrm{C}$, the second is for long bond to ${ }^{12} \mathrm{C}$. The first $C_{\infty}$ entries are for terminal ${ }^{12} \mathrm{C}$, the second for terminal ${ }^{13} \mathrm{C}$. The $\mathrm{C}^{+}+\mathrm{CO}$ entry is for ${ }^{12} \mathrm{C}^{+}+{ }^{13} \mathrm{CO}$.

and $C_{\infty v}$ structures lie at -77.8 and $-100.4 \mathrm{~kJ} \mathrm{~mol}^{-1}$, respectively, relative to $\mathrm{C}^{+}+\mathrm{CO}$ reactants. Our result confirms the conjecture ${ }^{31}$ that this structure, which has an energy above that of the $\mathrm{C}^{+}$and $\mathrm{CO}$ reactants at the SCF level of computations, would have an energy below that of reactants at a sufficiently high level of computation. Thus exchange of $\mathrm{C}$ atoms between $\mathrm{C}^{+}$and $\mathrm{CO}$ may well occur via a spinallowed pathway through the centrosymmetric $\mathrm{COC}^{+}$saddle point.

Another possible spin-allowed pathway for exchange of $\mathrm{C}$ atoms between $\mathrm{C}^{+}$and $\mathrm{CO}$ involves the electronic state ${ }^{2} A_{1}$ for a structure with $C_{2 v}$ symmetry. This structure is a local minimum with an energy of $-76.0 \mathrm{~kJ} \mathrm{~mol}^{-1}$ relative to that of $\mathrm{C}^{+}$and $\mathrm{CO}$ at the QCISD(T)/6-311G(2df)// CISD/6-31G* level. We have also located a saddle point with symmetry $C_{s}$; the electronic state is ${ }^{2} A^{\prime}$, with an electronic energy $17.3 \mathrm{~kJ} \mathrm{~mol}^{-1}$ above that of the $C_{2 v}$ local mini-

TABLE VIII. Ab initio structural parameters ${ }^{\mathrm{a}}$ for $\mathrm{C}_{2} \mathrm{O}^{+}$.

\begin{tabular}{lccc}
\hline \hline Symmetry (Term) & $\mathrm{C}_{1}-\mathrm{O}$ & $\mathrm{C}_{2}-\mathrm{O}$ & $\mathrm{C}_{1}-\mathrm{C}_{2}$ \\
\hline$C_{\infty v}\left({ }^{2} \Pi\right), \mathrm{CCO}^{+}$ & 1.118 & $\ldots$ & 1.566 \\
$C_{\infty v}\left({ }^{2} \Pi\right), \mathrm{COC}^{+}$ & 1.162 & 1.659 & $\ldots$ \\
$D_{\infty h}\left({ }^{2} \Pi_{g}\right), \mathrm{COC}^{+}$ & 1.261 & 1.261 & $\ldots$ \\
$C_{2 v}\left({ }^{2} A_{1}\right)$ & 1.314 & 1.314 & 1.641 \\
$C_{s}\left({ }^{2} A^{\prime}\right)$ & 1.218 & 1.482 & 1.894 \\
$C_{\infty v}\left({ }^{4} \Sigma^{-}\right), \mathrm{CCO}^{+}$ & 1.128 & $\ldots$ & 1.110 \\
$C_{s}\left({ }^{4} A^{\prime \prime}\right)$ & 1.269 & 1.539 & 1.359 \\
$C_{2 v}\left({ }^{4} A_{2}\right)$ & 1.394 & 1.394 & 1.319 \\
$D_{\infty h}\left({ }^{4} \Sigma_{v}^{-}\right), \mathrm{COC}^{+}$ & 1.242 & 1.242 & $\cdots$ \\
\hline \hline
\end{tabular}

${ }^{\mathrm{a} B o n d}$ distances in Ångstroms from optimized CISD/6-31G* geometries. The $D_{\infty h}\left({ }^{2} \Pi_{g}\right) \mathrm{COC}^{+}$and $C_{s}\left({ }^{2} A^{\prime}\right)$ structures are saddle points, the others local minima. The computed distance for CO is $1.136 \AA$. mum, or $-58.7 \mathrm{~kJ} \mathrm{~mol}^{-1}$ relative to $\mathrm{C}^{+}+\mathrm{CO}$. The $C_{s}$ structure is characterized by one long $\mathrm{CO}$ bond of $1.482 \AA$, one short bond of $1.218 \AA$, a COC angle of $88.5^{\circ}$, and a single imaginary $a^{\prime}$ vibrational wave number with magnitude $603 \mathrm{~cm}^{-1}$ at the CISD/6-31G* level. These two spin doublet structures lie on the same potential energy surface, namely, one correlated to the ${ }^{2} \Sigma^{+}$state of collinear $\mathrm{COC}^{+}$rather than

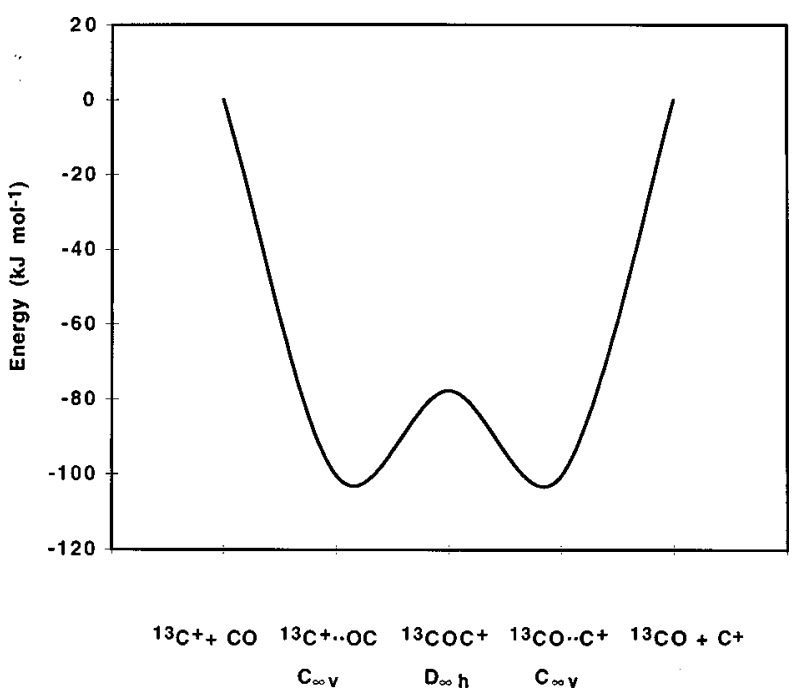

FIG. 1. Schematic potential energy curve showing exothermic formation of the linear adduct $\mathrm{COC}^{+}$in the $\mathrm{C}^{+} / \mathrm{CO}$ isotope exchange reaction. All energies (in $\mathrm{kJ} \mathrm{mol}^{-1}$ ) are relative to that of the ${ }^{13} \mathrm{C}^{+}$and $\mathrm{CO}$ reactants, and are a combination of electronic energies at the $\operatorname{QCISD}(\mathrm{T}) / 6-311 \mathrm{G}(2 d f) / /$ CISD/6-31G* level and zero-point vibrational energies at the CISD/6-31G* level. The overall energy change of $-0.3 \mathrm{~kJ} \mathrm{~mol}^{-1}$ is insignificant on the scale of the diagram. Exothermic formation of the linear adduct $\mathrm{OCHCO}^{+}$ in the $\mathrm{HCO}^{+} / \mathrm{CO}$ exchange reaction may be described by a similar diagram. 
to the ${ }^{2} \Pi$ state. [The latter gives rise to ${ }^{2} A_{2}$ and ${ }^{2} B_{1}$ (or ${ }^{2} B_{2}$ ) states in $C_{2 v}$ symmetry, but not ${ }^{2} A_{1}$.] Thus a second possible spin-allowed pathway for $\mathrm{C}$ isotope exchange between $\mathrm{C}^{+}$and $\mathrm{CO}$ might be that passing through a pair of $C_{s}$ saddle points separated by a $C_{2 v}$ local minimum. The highest energy along such a pathway is higher by $25.7 \mathrm{~kJ} \mathrm{~mol}^{-1}$ at the QCISD(T)/6-311G(2df)//CISD/6-31G* level (Table VII) than that along the pathway passing through the centrosymmetric $\mathrm{COC}^{+}$saddle point, but still below (by $58.7 \mathrm{~kJ} \mathrm{~mol}^{-1}$ ) that of the separated reactants.

Even allowing for some appreciable error in the computation of the energies of $\mathrm{C}_{2} \mathrm{O}^{+}$structures relative to the energies of $\mathrm{C}^{+}$and $\mathrm{CO}$, we conclude that there no barrier to isotope exchange if reaction (19) proceeds via either of the above spin-allowed pathways, namely, either through the $\mathrm{COC}^{+}$saddle point with $D_{\infty h}$ symmetry or through the $\mathrm{C}_{2} \mathrm{O}^{+}$ local minimum with $C_{2 v}$ symmetry. The $\mathrm{COC}^{+2} \Pi$ state may be interpreted as arising from the ${ }^{2} \Pi$ components of the atomic ${ }^{2} P$ term for $\mathrm{C}^{+}$; these have an empty $p_{\sigma}$ orbital which serves as an electron acceptor site from a filled $\sigma$ orbital at the $\mathrm{O}$ end of $\mathrm{CO}$, thus accounting for the linearity of this state of the adduct. The linear but noncentrosymmetric structure of this state is quite unusual; rare indeed are triatomic molecules, linear or bent, neutral or charged, of the formula $\mathrm{ABA}$, with $\mathrm{B}$ as the central atom, but with $\mathrm{AB}$ bonds of unequal length. By contrast, the ${ }^{2} A^{\prime}\left(C_{s}\right)$ or ${ }^{2} A_{1}\left(C_{2 v}\right)$ state is nonlinear, as it is derived from the ${ }^{2} \Sigma^{+}$component of the atomic ${ }^{2} \mathrm{P}$ term for $\mathrm{C}^{+}$and thus has an electron in the $\mathrm{C}^{+} p_{\sigma}$ orbital.

We have also considered spin quartet states of $\mathrm{C}_{2} \mathrm{O}^{+}$. First, we refined the CISD/6-31G*//HF/6-31G* calculations of Cao and $\operatorname{Tian}^{34}$ on the linear ${ }^{4} \Sigma^{-}$local minimum and the isosceles triangular ${ }^{4} A_{2}$ transition state with $C_{2 v}$ symmetry. Our optimized CISD/6-31G* geometries (Table VIII) differ slightly but not significantly from the reported $\mathrm{HF} / 6-31 \mathrm{G}^{*}$ geometries; for the linear quartet the CC distance is $1.356 \AA$ and the CO distance is $1.128 \AA$, while for the triangular transition state the CC distance is $1.394 \AA$, the CO distance is $1.319 \AA$, and the COC angle is $56.5^{\circ}$. Although the ${ }^{4} A_{2}$ state corresponds to a saddle point at the HF/6-31G* level, with imaginary $b_{2}$ wave number of $1415 i \mathrm{~cm}^{-1}$, it corresponds to a local minimum at the optimized CISD/6-31G* level, with real $b_{2}$ wave number of $2242 \mathrm{~cm}^{-1}$. While the energy of the linear quartet is quite low, namely, $-228.3 \mathrm{~kJ} \mathrm{~mol}^{-1}$ relative to $\mathrm{C}^{+}$and $\mathrm{CO}$ at the QCISD(T)/6-311G(2df)//CISD/6-31G* level, the connectivity $\mathrm{CCO}$ does not lead to an exchange of $\mathrm{C}$ atoms. The triangular structure with $C_{2 v}$ symmetry, which has equivalent $\mathrm{C}$ atoms and hence could lie on an exchange pathway, has a very high energy, namely $+80.4 \mathrm{~kJ} \mathrm{~mol}^{-1}$ at the same level. This high energy, plus the two electronic spin changes needed to pass from spin doublet reactants through this quartet intermediate to doublet products, precludes this structure as a likely route to isotope exchange between $\mathrm{C}^{+}$and $\mathrm{CO}$.

We did locate two additional spin quartet local minima, the first being a ${ }^{4} A$ " state with a nonlinear structure of only $C_{s}$ symmetry, unequal CO bond distances of 1.269 and 1.539 $\AA$, a COC bond angle of $56.9^{\circ}$ at the CISD/6-31G* level, and an energy of $+81.5 \mathrm{~kJ} \mathrm{~mol}^{-1}$ relative to $\mathrm{C}^{+}$and $\mathrm{CO}$ at the QCISD(T)/6-311G(2df)//CISD/6-31G* level. The energy of this structure is close to that of the isosceles triangular ${ }^{4} A_{2}$ state at this as well as at lower computational levels. Indeed the two structures represent two points on the same quartet hypersurface, both being local minima at the CISD/6-31G* level, although the higher symmetry $C_{2 v}$ structure is a saddle point at the lower $\mathrm{HF} / 6-31 \mathrm{G}^{*}$ level. Finally at a very high energy of $+131.2 \mathrm{~kJ} \mathrm{~mol}^{-1}$ relative to $\mathrm{C}^{+}$and $\mathrm{CO}$ at the QCISD(T)/6-311G(2df)//CISD/6-31G* level there is a ${ }^{4} \Sigma_{u}{ }^{-}$state of a centrosymmetric structure with connectivity $\mathrm{C}-\mathrm{O}-\mathrm{C}\left(D_{\infty h}\right.$ symmetry $)$ and $\mathrm{CO}$ distances of $1.242 \AA$ at the CISD/6-31G* level. As we have been unable to locate any spin quartet structure for $\mathrm{C}_{2} \mathrm{O}^{+}$ having equivalent $\mathrm{C}$ atom positions and an energy comparable to or below that of $\mathrm{C}^{+}$and $\mathrm{CO}$, we conclude that $\mathrm{C}$ atom exchange takes place along an allowed spin doublet pathway involving exothermic formation of the adduct $\mathrm{C}_{2} \mathrm{O}^{+}$, thus accounting for the observed anti-Arrhenius behavior of the rate constants.

\section{SUMMARY}

We have employed $a b$ initio computational quantum chemical methods to calculate reduced partition function ratios for all isotopomers of $\mathrm{CO}, \mathrm{HCO}^{+}$, and $\mathrm{HOC}^{+}$involving the nuclides ${ }^{1} \mathrm{H},{ }^{2} \mathrm{H}(\mathrm{D}),{ }^{12} \mathrm{C},{ }^{13} \mathrm{C},{ }^{16} \mathrm{O}$, and ${ }^{18} \mathrm{O}$. The ratios were obtained from unscaled vibrational frequencies computed at the CISD/6-31G** level (CISD/6-31G* for CO) and used to calculate equilibrium constants for isotope exchanges involving the reaction pairs $\mathrm{HCO}^{+} / \mathrm{CO}, \mathrm{HOC}^{+} / \mathrm{CO}$, and $\mathrm{C}^{+} / \mathrm{CO}$. Both simple proton transfers and more complex isotopic variants involving the breaking and reforming of $\mathrm{CO}$ bonds have been considered. The probable pathways for the $\mathrm{HCO}^{+} / \mathrm{CO}$ and $\mathrm{C}^{+} / \mathrm{CO}$ exchange reactions have been explored using higher accuracy quantum chemical calculations at the QCISD(T)/6-311G(2df)//CISD/6-31G* level. The $\mathrm{HCO}^{+} / \mathrm{CO}$ reaction proceeds through exothermic formation of the linear adduct $\mathrm{OCHCO}^{+}$with $D_{\infty h}$ symmetry. Similarly, the $\mathrm{C}^{+} / \mathrm{CO}$ reaction proceeds along a spin-allowed pathway with exothermic formation of the linear adduct $\mathrm{COC}^{+}$with $D_{\infty h}$ symmetry. An alternate spin allowed pathway for the latter reaction passes through a pair of equivalent transition states with only $C_{s}$ symmetry separated by a local minimum with $C_{2 v}$ symmetry.

\section{ACKNOWLEDGMENTS}

The author thanks Professor Charles Cowley of the University of Michigan Department of Astronomy for the suggestion of this problem and for many helpful discussions. He also thanks Mr. William Ahrens for assistance with the computations.

\footnotetext{
${ }^{1}$ H. C. Urey, J. Chem. Soc. 1947, 562.

${ }^{2}$ H. Craig, Geochim. Cosmochim. Acta 6, 186 (1957); also see G. Faure, Principles of Isotope Geology, 2nd ed. (Wiley, New York, 1986), pp. 491-512.

${ }^{3}$ Y. Bottinga, J. Phys. Chem. 72, 800 (1968).

${ }^{4}$ Y. Bottinga, Geochim. Cosmochim. Acta 33, 49 (1969).

${ }^{5}$ Y. Bottinga, Earth Planet. Sci. Lett. 5, 301 (1969).
} 
${ }^{6}$ Y. Bottinga and H. Craig, Earth Planet. Sci. Lett. 5, 285 (1969).

${ }^{7}$ P. Richet, Y. Bottinga, and M. Javoy, Annu. Rev. Earth Planet Sci. 5, 65 (1977).

${ }^{8}$ J. Bigeleisen, M. W. Lee, and F. Mandel, Annu. Rev. Phys. Chem. 24, 407 (1973).

${ }^{9}$ W. D. Watson, Rev. Mod. Phys. 48, 513 (1976); also see W. D. Watson, Topics in Interstellar Matter, edited by H. van Woerden (Reidel, Dordrecht, 1977), pp. 135-147; W. D. Watson, Interstellar Molecules, edited by B. H. Andrew (Reidel, Dordrecht, 1980), pp. 341-353.

${ }^{10}$ D. Smith and N. G. Adams, Astrophys. J. 242, 424 (1980).

${ }^{11}$ S. Wyckoff, E. Lindholm, P. A. Wehinger, B. A. Peterson, J.-M. Zucconi, and M. C. Festou, Astrophys. J. 339, 488 (1989).

${ }^{12}$ G. J. White and G. Sandell, Astron. Astrophys. 299, 179 (1995).

${ }^{13}$ S. J. Mojzsis, G. Arrhenius, K. D. McKeegan, T. M. Harrison, A. P. Nutman, and C. R. L. Friend, Nature (London) 384, 55 (1996).

${ }^{14}$ D. S. McKay, E. K. Gibson, Jr., K. L. Thomas-Keprta, H. Vali, C. S. Romanek, S. J. Clemett, X. D. F. Chillier, C. R. Maechling, and R. N. Zare, Science 273, 924 (1996); for different conclusions about the same Martian meteorite (ALH84001) see R. P. Harvey and H. Y. McSween, Jr., Nature (London) 382, 49 (1996).

${ }^{15} \mathrm{C}$. H. Townes, Topics in Interstellar Matter, edited by H. van Woerden (Reidel, Dordrecht, 1977), pp. 113-123.

${ }^{16}$ P. G. Wannier, Annu. Rev. Astron. Astrophys. 18, 399 (1980).

${ }^{17}$ E. Herbst and W. Klemperer, Astrophys. J. 185, 505 (1973); 188, 255 (1974).

${ }^{18}$ S. Green, Annu. Rev. Phys. Chem. 32, 103 (1981).

${ }^{19}$ D. Smith and N. G. Adams, Int. Rev. Phys. Chem. 1, 271 (1981).

${ }^{20}$ H. W. Kroto, Int. Rev. Phys. Chem. 1, 309 (1981).
${ }^{21}$ A. Dalgarno, J. Chem. Soc., Faraday Trans. 89, 2111 (1993).

${ }^{22}$ C. R. Cowley, An Introduction to Cosmochemistry (Cambridge University Press, Cambridge, 1995), pp. 125-149.

${ }^{23}$ W. D. Langer and A. A. Penzias, Astrophys. J. 357, 477 (1990); 408, 539 (1993).

${ }^{24}$ T. Xie, M. Allen, and W. D. Langer, Astrophys. J. 440, 674 (1995).

${ }^{25}$ R. P. A. Bettens and E. Herbst, Astrophys. J. 468, 686 (1996); 478, 585 (1997).

${ }^{26}$ T. L. Wilson and R. T. Rood, Annu. Rev. Astron. Astrophys. 32, 191 (1994).

${ }^{27}$ B. E. Turner, Astrophys. J. 468, 694 (1996).

${ }^{28}$ GAUSSIAN 94, Revision B.3, M. J. Frisch, G. W. Trucks, H. B. Schlegel, P. M. W. Gill, B. G. Johnson, M. A. Robb, J. R. Cheeseman, T. Keith, G. A. Petersson, J. A. Montgomery, K. Raghavachari, M. A. Al-Laham, V. G. Zakrzewski, J. V. Ortiz, J. B. Foresman, C. Y. Peng, P. Y. Ayala, W. Chen, M. W. Wong, J. L. Andres, E. S. Replogle, R. Gomperts, R. L. Martin, D. J. Fox, J. S. Binkley, D. J. Defrees, J. Baker, J. P. Stewart, M. Head-Gordon, C. Gonzalez, and J. A. Pople (Gaussian, Inc., Pittsburgh, 1995).

${ }^{29}$ A. J. Apponi and L. M. Ziurys, Astrophys. J. 481, 800 (1997).

${ }^{30}$ E. J. Bielske, S. A. Nizkorodov, F. R. Bennett, and J. P. Maier, J. Chem. Phys. 102, 5152 (1995).

${ }^{31}$ N. N. Haese and R. C. Woods, Chem. Phys. Lett. 91, 190 (1982).

${ }^{32}$ R. G. A. R. Maclagan and P. Sudkeaw, J. Chem. Soc., Faraday Trans. 89, 3325 (1993).

${ }^{33}$ R. Flammang, Y. V. Haverbeke, M. W. Wong, A. Rühmann, and C. Wentrup, J. Phys. Chem. 98, 4814 (1994).

${ }^{34}$ Z. Cao and A. Tian, J. Mol. Struct.: THEOCHEM 334, 45 (1995). 